\title{
Providing lifestyle advice to women with PCOS: an overview of practical issues affecting success
}

\author{
Carolyn Ee 1D $^{*}$, Stephanie Pirotta ${ }^{2}$, Aya Mousa ${ }^{3}$, Lisa Moran ${ }^{3}$ and Siew Lim³
}

\begin{abstract}
Polycystic Ovary Syndrome (PCOS) is a common endocrine disorder affecting up to $13 \%$ of women. Lifestyle interventions are first-line treatments, however attrition in women with PCOS is high. This review summarises current evidence on barriers to lifestyle management in PCOS and suggested strategies for overcoming these challenges, mapped to the Capability, Opportunity, Motivation and Behaviour model.

Physical capability for lifestyle changes may be impacted by altered gut hormone regulation and energy expenditure in PCOS. This may contribute to difficulties with weight management. The higher prevalence of eating disorders, disordered eating, fatigue and sleep disturbances are further barriers. Psychological capability may be reduced due psychological symptoms and lack of critical health literacy. Women with PCOS face similar challenges in terms of Opportunity to make lifestyle changes as other women of reproductive age. However, these are complicated by features more common in PCOS including body dissatisfaction. Motivation to adopt healthy lifestyles may be impacted by suboptimal risk perception and intrinsic motivation.

To address these barriers, screening for and management of eating disorders, disordered eating, depression, and Obstructive Sleep Apnoea should be undertaken as per international evidence-based guidelines. A weight-neutral approach may be appropriate with disordered eating. Building capability among health professionals to better partner with women with PCOS on their management is essential in addressing health literacy gaps. Behavioural strategies that target risk perception and build intrinsic motivation should be utilised. More research is required to understand optimal self-management strategies, risk perception, energy homeostasis and overcoming attrition in women with PCOS.
\end{abstract}

Keywords: Polycystic ovary syndrome, Lifestyle, Behaviour change, Obesity, Weight, Health literacy, Risk perception, Depression, Self-management, Fatigue, COM-B

\section{Background}

Polycystic Ovary Syndrome (PCOS) is a multisystem disorder with reproductive, metabolic, and psychological manifestations [1] affecting up to $13 \%$ of women of reproductive age [2]. A woman is diagnosed with PCOS if she has any two of the three criteria established by the

\footnotetext{
* Correspondence: c.ee@westernsydney.edu.au

'NICM Health Research Institute, Western Sydney University, Locked Bag 1797, NSW 2751 Penrith, Australia

Full list of author information is available at the end of the article
}

European Society for Human Reproduction and Embryology/American Society for Reproductive Medicine (ESHRE/ASRM) international consensus working group (also known as the Rotterdam criteria). These criteria are: hyperandrogenism (biochemical or clinical); irregular anovulatory cycles ( $>35$ days or $<21$ days); and polycystic ovarian morphology [3]. Other reproductive disorders such as hyperprolactinemia must be excluded.

In addition to the reproductive features, PCOS is also associated with psychological and metabolic

C C The Author(s). 2021 Open Access This article is licensed under a Creative Commons Attribution 4.0 International License, which permits use, sharing, adaptation, distribution and reproduction in any medium or format, as long as you give appropriate credit to the original author(s) and the source, provide a link to the Creative Commons licence, and indicate if changes were made. The images or other third party material in this article are included in the article's Creative Commons licence, unless indicated otherwise in a credit line to the material. If material is not included in the article's Creative Commons licence and your intended use is not permitted by statutory regulation or exceeds the permitted use, you will need to obtain permission directly from the copyright holder. To view a copy of this licence, visit http://creativecommons.org/licenses/by/4.0/ The Creative Commons Public Domain Dedication waiver (http://creativecommons.org/publicdomain/zero/1.0/) applies to the data made available in this article, unless otherwise stated in a credit line to the data. 
complications including decreased health-related quality of life [4] and increased prevalence of anxiety and depression [5], as well increased risk of future type 2 diabetes and coronary artery disease [6]. Insulin resistance is a key pathophysiological feature of PCOS and is present in even lean women with PCOS in a form that is proposed to be mechanistically distinct from obesityassociated insulin resistance [7]. Women with PCOS have a higher prevalence of overweight and obesity and a higher rate of longitudinal weight gain compared to women without PCOS [8]. Weight gain and obesity further worsen insulin resistance and consequently the overall features of PCOS [9]. Hence, weight management (weight gain prevention, modest weight loss or weight maintenance) is a first-line strategy as recommended in international evidence-based guidelines [10]. Such weight management strategies should encompass multidisciplinary lifestyle interventions, comprising of dietary, exercise and behavioural therapies [10].

While effective lifestyle modification is a key component of PCOS management, the evidence of higher obesity prevalence and longitudinal weight gain in community-recruited populations [11], combined with high attrition rates in clinical lifestyle interventions [12] suggests that women with PCOS experience challenges with weight management and implementing and sustaining lifestyle changes. Literature shows all women of reproductive age with or without PCOS are at greater risk of dropout when compared to women of older age [13]. This is likely due to factors such as family responsibilities, fatigue, lack of time, poor partner support, low mood and lack of exercise facilities to name a few. The overlap in barriers in all women of reproductive age suggests attrition is due to lifestage rather than a PCOS diagnosis [14]. In this paper, we present a review of barriers to lifestyle management in women with PCOS and suggested strategies to overcome these challenges. Briefly, we searched the MEDLINE database from inception until March 2021 using the following keywords: Polycystic Ovary Syndrome OR PCOS, appetite, energy expenditure, peptide yy, ghrelin, glucagon like peptide 1, basal metabolic rate, post prandial thermogenesis, respiratory quotient, health literacy, management AND lifestyle, implementation AND lifestyle, facilitators, barriers, qualitative, disordered eating, eating disorders, self-management, risk perception, perceived risk, fatigue, sleep, obstructive sleep apnoea OR OSA, anxiety, depression, body image distress, psychological. We mapped these barriers and strategies against the Capability, Opportunity, Motivation and Behaviour (COMB) model, which posits that one's ability to engage in a behaviour (capability), the enabling circumstance (opportunity), and the willingness to engage (motivation) all need to be present for a particular behaviour to occur [15]. Developed based on 19 behaviour change frameworks, the COMB model consists of a hub (Capability, opportunity and motivation/COM) and a 'Behaviour Change Wheel', around which nine intervention functions are positioned, which inform strategies to behaviour change corresponding to the COM domains [16].

\section{Barriers in capability, opportunity, motivation and behaviour \\ Capability: physical \\ Appetite regulation and energy expenditure}

There are a number of potential physiological reasons unique to women with PCOS that may explain difficulties with weight management. Insulin resistance and hyperinsulinaemia may predispose women with PCOS to gain weight, supported by insulin therapy-inducing weight gain [17] through anabolic effects of insulin and changes in energy expenditure, glycosuria, and food intake [18-23]. Androgen excess may favour abdominal fat deposition [24], which could additionally contribute to insulin resistance in PCOS.

There may also be abnormalities in energy homeostasis in women with PCOS. The limited literature in this area has reported decreases in basal metabolic rate [25] or postprandial thermogenesis [26] for women with PCOS compared to those without, although this is not consistently found [26-29]. The respiratory exchange ratio or respiratory quotient (RQ) refers to substrate oxidation or the carbohydrate-to-fat oxidation ratio [30], with a higher RQ (indicative of reduced fat oxidation) previously associated with weight gain [31, 32] in the general population. Women with PCOS have been reported to have higher RQ [33] compared to women without PCOS. Metabolic flexibility refers to the metabolic capacity to switch from lipid oxidation in fasting conditions to lipid availability in non-fasting conditions and is assessed by comparing RQ in the fasting state and an insulin rich state. A systematic review of five studies reported higher metabolic inflexibility in women with PCOS compared to controls and similar metabolic inflexibility compared to women with type 2 diabetes or obesity [34]. Further, these alterations in energy expenditure or metabolic inflexibility have been associated with insulin resistance [25, 26, 34] and hyperandrogenism [34].

Appetite regulation has also been reported to be impaired in women with PCOS, with alterations in hunger and gut hormones. A systematic review of 20 studies involving 894 women with and 574 women without PCOS reported lower ghrelin in PCOS (standardised mean difference -0.40; $95 \%$ confidence interval $-0.73,-0.08$ ) [35], related to factors including insulin resistance. There is 
evidence that suggests intra-adipose androgen excess plays a role in the cycle of insulin resistance and weight gain [36]. Postprandial cholecystokinin has also been reported to be reduced [37] and fasting or postprandial glucagon-like peptide-1 (GLP-1) increased [38] or decreased [39] in women with PCOS. Further, women with PCOS have been reported to be less satiated and more hungry after eating compared to women without PCOS [40] and have a higher energy intake and earlier return of hunger [41]. However, the literature again is inconsistent, with other studies reporting no differences in gut hormones or appetite in women with and without PCOS [38, 42-44]. Of note, there is also research reporting that there may be additional mechanisms contributing to increased adiposity in PCOS, such as altered regulation of appetite regulatory brain regions occurring in conjunction with insulin resistance [45]. There is therefore an emerging, albeit inconsistent, body of research suggesting mechanisms for why obesity and weight gain may be increased in this population.

\section{Eating disorders}

Women with PCOS are reported to have a higher prevalence of both disordered eating behaviours [46-48] and eating disorders $[49,50]$ compared to women without PCOS in the majority of, but not all, prior literature [51-54]. In the limited research to date, studies use a variety of screening tools [e.g. Eating Attitudes Test-26 [47], the Mini International Neuropsychiatric Interview (MINI) [55] and the Eating Disorder Examination Questionnaire (EDE-Q) [56], with each having a different screening criterion. This lack of uniformity in assessments contributes to the reason as to why further clarification is required to better understand whether disordered eating or eating disorders are more prevalent in women with PCOS compared to those without the condition. Furthermore there is a lack of understanding as to why women with PCOS may experience greater rates of disordered eating behaviours and eating disorders compared to women without PCOS. A recent Australian study explored the cross-sectional relationship between disordered eating or eating disorders and a range of demographic risk factors (PCOS diagnosis, body mass index [BMI], age, country of birth). Authors reported that disordered eating, but not eating disorders, were more prevalent in women with PCOS when compared with controls [57]. Of the disorders, binge-eating disorder (BED) was the most commonly reported but not significantly different to controls. BED is the most common form of eating disorders within the general population and may explain the frequency and lack of significance between the two groups [58]. The crosssectional study also reported higher BMI and older age increased the odds of disordered eating whilst increased
BMI and younger age increased the odds of an eating disorder [57]. It is important to highlight that the controls were psychology university students and may not be a true representation of the general population. A meta-analysis also reported that women with PCOS are at 3.05 greater odds of being diagnosed with an eating disorder compared with women without PCOS, but was unable to distinguish the specific subtypes of eating disorders diagnosed due to a lack in power. More rigorous studies investigating the prevalence and presentation of disordered eating and eating disorders in women with PCOS are needed to better inform screening and management.

\section{Fatigue and sleep}

Fatigue has been reported by women with PCOS as a barrier to adopting lifestyle changes [14], which may be due to physiological or psychological origins. Women with PCOS are more likely to report fatigue than women without PCOS [59]. Fatigue is intrinsically linked with sleep, and women with PCOS have a higher prevalence of poor sleep quality and sleep disorders compared to women without [60-62]. In particular, it is estimated that up to $35 \%$ of women with PCOS may have obstructive sleep apnoea (OSA) [62], compared to 9-38\% in the general population [63]. Women who are obese and of older age are more at risk of developing OSA [62]. Sleep disturbances in women with PCOS may also occur independently of OSA $[64,65]$ and may be related to psychological distress and upregulation of the hypothalamic-pituitary axis, and/or increased sympathetic outflow due to insulin resistance [66] although exact mechanisms are still unclear.

\section{Capability: psychological \\ Depression and depressive symptoms}

Fatigue and sleep disturbances may also indicate depression, and are the most commonly reported depressive symptoms in women with PCOS [59]. The prevalence of depression and depressive symptoms is higher in PCOS [67] and PCOS is also associated with more severe symptoms of depression [68]. A recent meta-analysis of 57 studies reporting on 172,040 women reported that women with PCOS were at 2.79 greater odds for being clinically diagnosed with depression when compared to controls [68]. Another meta-analysis estimated a prevalence of $36 \%$ for depression in PCOS [69]. The risk of developing depression may be associated with higher BMI [70], although this association is weak. The development of depression and depressive symptoms may also be related to the presence of hyperandrogenism, hyperinsulinemia and elevated levels of inflammation in PCOS [71]. 


\section{Body image distress}

Women with PCOS are more likely to report a lack of confidence about maintaining physical activity [72] which may be related to negative body image, and feelings of shame and worthlessness [73]. While body image distress is not limited to women with PCOS [74], there is a high prevalence of body image distress among women with PCOS and it has been suggested that this might mediate the development of depression and anxiety [75]. Research suggests that women with PCOS experience feelings of being inferior and abnormal compared with women without PCOS [76] and this may lead to beliefs that they are unable to participate in physical activity [73]. All of these factors may contribute to difficulties initiating and maintaining lifestyle changes.

\section{Self-management}

Self-management is a continuous process of self-directed behaviour change known to improve one's personal emotional, behavioural and medical management, aiming to avoid disease-related complications, regulate symptoms and reduce the severity of disease [77-79]. These actions may take form as cognitive (e.g. problem solving, decision making) and/or behavioural strategies (e.g. forming relationships with health practitioners and having healthy foods easily available) to meet one's own health needs [79, 80]. All of these core self-management behaviours are heavily influenced by one's knowledge [81] and self-efficacy [82] and must be targeted in order to prevent or manage chronic disease. Effective selfmanagement strategies in the general population include the independent monitoring of symptoms, development of personalised action plans upon worsening of symptoms, understanding and implementing psychological coping strategies to better manage stress, and enhancing personal responsibility in daily lifestyle choices and medication adherence [83]. Unfortunately, the use of self-management strategies and their impact on nutrition and physical activity are yet to be investigated in women with PCOS.

\section{Health literacy}

Health literacy provides a comprehensive lens on selfmanagement among women with PCOS. Health literacy is an important determinant of health equity and comprises a multi-dimensional concept described by the World Health Organisation as "the cognitive and social skills which determine the motivation and ability of individuals to gain access to, understand and use information in ways which promote and maintain good health" [84]. Research in the general population found that health literacy is associated with health behaviours and health outcomes including hospitalisation rates, overall health status, obesity, dietary intake, and physical activity
[85-88]. As PCOS is a complex disorder with variable and wide-ranging symptoms, its self-management is likely to also be complex requiring high levels functional, interactive, and critical health literacy. However, there has been very limited research on health literacy in women with PCOS, as discussed below [89, 90].

There are three main categories of health literacy: functional, interactive and critical health literacy [91]. While evidence presented here are on the individual types of health literacy, dynamic interactions exist between the different types of health literacies. For example, poor knowledge on PCOS (functional health literacy) could limit meaningful engagement with health professionals (interactive health literacy); on the other hand, poor engagement of allied health professionals (interactive health literacy) limit opportunities to obtain the appropriate knowledge and skills in lifestyle management (functional health literacy).

Functional health literacy in PCOS Functional health literacy describes the basic knowledge and skills in health including literacy and numeracy skills to process health information such as reading food labels [92]. Higher levels of functional health literacy were associated with lower BMI in women with PCOS as shown in one study in women from Arabic backgrounds [89]. Past studies have also shown that women with PCOS attempt a wide range of weight loss approaches on their own [93-95]. This results in an unstructured approach usually lacking in key behaviour change techniques such as goal setting and self-monitoring such as keeping a food diary $[90,96]$. The omission of key behaviour change strategies could explain the lack of weight loss success frequently reported by women with PCOS [90].

Interactive health literacy in PCOS Interactive health literacy describes the ability to apply the knowledge through supportive relationships, which could include accessing health services and support, the ability to engage healthcare professionals to manage health and having social support for health [91, 97]. In terms of their interaction with health professionals, women with PCOS often report challenges and frustration around delayed diagnosis of PCOS, inadequate and inconsistent information and poor communication between healthcare professionals and women with PCOS [98-100]. This suggests poor interactive health literacy in the selfmanagement of women with PCOS. Peer support is another important aspect of interactive health literacy, comprising an important part of supportive relationships in the management of PCOS. There is increasing recognition of the role of PCOS support groups in promoting awareness, advocacy and general support among its members [101]. However, women with PCOS have 
reported a sense of isolation and lack of access to support from peers [102].

Critical health literacy in PCOS Critical health literacy builds on functional and interactive health literacies to advocate for individual and social health, such as making shared decisions on one's health with health professionals [91, 103, 104]. In our previous study on health literacy in women with PCOS, none of the participants attributed their past successes in lifestyle and weight management to a strong partnership with a healthcare professional [90], which is an essential component of critical health literacy $[91,103,104]$. As this health literacy category builds on capacities drawn from functional and interactive health literacies, significant gaps in the latter, particularly those around relationships with healthcare providers, may have prevented the development of a partnership with healthcare professionals. Similar research and practice gaps in the domain of critical health literacy have been highlighted in lifestyle management of other women of reproductive age due to a lack of patient involvement in intervention development [105].

\section{Opportunity}

Women with PCOS report similar barriers to lifestyle and weight management as those generally faced by women of reproductive age without PCOS, including conflict with work and family commitments, or disliking the "mundaneness" of a restricted diet $[14,106]$. These barriers may contribute to the high risk of weight gain in women of reproductive age [107]. However, these general barriers are further complicated with features of PCOS, particularly the psychological manifestations of body dissatisfaction and depressive symptoms. For example, not having a suitable place to exercise intersects with feeling embarrassed about being seen outdoors or in a gym, and this in turn is related to negative thoughts about feeling depressed [108]. Thus, reduced opportunity to exercise due to the lack of safe environment to do so is further compounded by psychological issues and self-perception in PCOS.

\section{Motivation}

\section{Risk perception}

Risk perception is one's subjective judgement about the likelihood that an adverse event will occur and the severity of consequences should it occur [109]. Risk perceptions are a precursor to health-related behaviours as they influence how one views disease and the protective actions they may or may not take to reduce risk [110, 111]. There is limited understanding regarding the health-related knowledge and beliefs of women with PCOS. Despite poorer overall health and greater health- related impediments in women with PCOS, the few studies published to date report conflicting findings regarding the health-related beliefs of women with PCOS compared with those without [112, 113]. For instance, some studies report that risk perceptions of future metabolic complications such as diabetes and cardiovascular disease (CVD) are suboptimal in women with PCOS [113], while others do not [114, 115]. A recent study of 475 women [116] reported that, compared with healthy controls, women with PCOS had a greater perceived risk for adverse health outcomes and weight gain, yet believed a healthy lifestyle was less beneficial for preventing weight gain.

Notwithstanding their own perceptions of risk, evidence suggests that PCOS is associated with greater risk of metabolic diseases such as type 2 diabetes in the long term $[117,118]$. Moreover, despite their unique risk profiles, women with PCOS are often provided with general population government dietary recommendations that they perceive as inadequate and dismissive of their PCOS needs $[115,119,120]$. As a result, women with PCOS tend to be ambivalent about meeting these dietary recommendations, with only a few following them, even though they reported high confidence in being able to adopt the recommendations and being more concerned about developing adverse health outcomes compared to women without PCOS [116].

\section{Intrinsic motivation}

Women with PCOS also appear to lack intrinsic motivation to undertake lifestyle change, such as enjoyment of physical activity, instead viewing physical activity only as a means to weight loss. This is evidenced by previous research reporting that a major barrier to physical activity adoption among women with PCOS is the perceived barrier that exercise is tiring and hard work [121], and fear of injury [72].

\section{Behaviour: attrition}

All the barriers in Capability, Opportunity and Motivation contribute to the key behavioural issue underlying lifestyle management in PCOS-attrition. Attrition is a common barrier to successful weight management, reported across all weight management interventions targeting women of reproductive age with or without PCOS [122]. Women with PCOS may experience additional challenges, with attrition as high as $46 \%$ [123] in this population, compared to $30 \%$ in clinical weight loss interventions in women without PCOS [12, 124-126].

It is known that individuals who prematurely terminate weight loss interventions do not attain the required skills and strategies to effectively overcome barriers to lifestyle change. This impacts long term weight management, with intervention completion positively correlated 
with weight loss [127]. Other health implications include a reduced quality of life (physical, mental, and social wellbeing), increased loss of income due to work absenteeism [128-130], and an increased risk of obesityassociated disease [127, 131].

To date, literature has identified participant characteristics (e.g. younger age, lower BMI, male, unemployed status and lower education) [132] and predictors (e.g. increased previous weight loss attempts, poorer quality of life, more stringent weight outcomes, lower carbohydrate intake, increased stress, and lower state of motivation to change) $[122,132,133]$ that may lead to attrition in the general population [134]. However, no research has been conducted on the differential predictors of attrition in women with or without PCOS. Only one study reported that depression was associated with attrition in PCOS [124].

\section{Implications for research and practice in capability, opportunity and motivation Capability: physical Appetite regulation and energy expenditure}

When communicating to women with PCOS, it is important to be aware of these mechanisms as to best acknowledge the potential pathophysiology of challenges they may experience when trying to manage weight. Further research is needed both in women with PCOS and the general population on strategies to aid weight management through modulating energy expenditure or appetite regulation.

\section{Fatigue and sleep disturbance}

If fatigue, sleepiness and non-restorative sleep are identified, screening for OSA should be considered, followed by a referral to a sleep specialist if required. The tool recommended by international evidence-based guidelines on PCOS is the Berlin Questionnaire [135], although this has not been validated in PCOS. Fatigue and sleep disturbances may also be due to depression, and screening for depression should be conducted as required, per evidence-based guidelines (see Table 1). Fatigue and sleep disturbances may also be due to depression, and screening for depression should be conducted as required, per evidence-based guidelines (see Table 1). Women with sleep disturbances that are not due to OSA may still benefit from a sleep specialist referral, and sleep hygiene should be prescribed. Cognitive behavioural therapy may also be helpful [66]

\section{Eating disorders and disordered eating}

Lifestyle recommendations may need to be sensitive to disordered eating or eating disorders so as to not perpetuate disordered eating psychopathologies [48]. Eating disorders are psychological disorders characterised by
Table 1 Recommended screening for depression, negative body image and eating disorders [136]

Assessment of anxiety and or depressive symptoms involves assessment of risk factors, symptoms and severity. Symptoms can be screened according to regional guidelines, or by using the following stepped approach:

Step 1: Initial questions could include: Over the last 2 weeks, how often have you been bothered by the following problems?

- feeling down, depressed, or hopeless?

- little interest or pleasure in doing things?

- feeling nervous, anxious or on edge?

- not being able to stop or control worrying?

Criteria: If any of the responses are positive, further screening should

involve:

- assessment of risk factors and symptoms using age, culturally and regionally appropriate tools, such as the Patient Health Questionnaire (PHQ) or the Generalised Anxiety Disorder Scale (GAD7) and/or refer to an appropriate professional for further assessment.

Negative body image, can be screened according to regional guidelines or by using the following stepped approach:

Step 1: Initial questions could include:

- Do you worry a lot about the way you look and wish you could think about it less?

- On a typical day, do you spend more than 1 hour per day worrying about your appearance? (More than 1 hour a day is considered excessive)

-What specific concerns do you have about your appearance?

-What effect does it have on your life?

- Does it make it hard to do your work or be with your friends and family?

Criteria: If an issue is identified, health professionals could further assess by:

- Identifying any focus of concern of the patient and respond appropriately

- Assessing the level of depression and/or anxiety

- Identifying distortion of body image or disordered eating

Eating disorders and disordered eating can be screened using the following stepped approach.

Step 1: The SCOFF (Sick, Control, One stone, Fat, Food) screening tool can be used or initial screening questions can include:

Does your weight affect the way you feel about yourself?

Are you satisfied with your eating patterns?

Criteria: If the SCOFF tool or any of these questions are positive, further screening should involve:

assessment of risk factors and symptoms using age, culturally and regionally appropriate tools;

referral to an appropriate health professional for further mental health assessment and diagnostic interview. If this is not the patient's usual healthcare provider, inform the primary care physician.

abnormal or disturbed eating behaviours with or without compensatory behaviours, as determined by the Diagnostic and Statistical Manual of Mental Disorders-5 [137]. Behaviours that classify an eating disorder may include food restriction, binge-eating, purging, laxative use, diet pills and excessive exercise. Disordered eating is a condition characterised by these same characteristics but are of a lesser frequency or a lower level of severity as that of an eating disorder [137]. One example in which lifestyle recommendations may be applied whilst not exacerbating disordered eating symptomologies is by incorporating a weight-neutral approach (e.g. intuitive eating, self-care activities) $[57,138]$, rather than the traditional, dietary restriction. A 2019 systematic review 
found weight-neutral programs reduced serum lipid measures and blood pressure comparable to weight loss interventions. In both weight-neutral and weight loss focus programs non-significant reductions in $\mathrm{HbA} 1 \mathrm{c}$ were observed [139]. Further studies are needed to confirm the impact of weight-neutral programs in women with PCOS. Furthermore, understanding the demographic risk factors associated with these pathological eating behaviours may help clinicians identify women with PCOS most at risk of eating disorders or disordered eating. Until more research is available, clinicians are recommended to screen all women with PCOS for possible disordered eating behaviours, with particular attention to women with elevated BMI (see Table 1). Moreover, future research should incorporate interviews with a clinical psychologist to clinically diagnose disordered eating and eating disorders.

\section{Capability: psychological Self-management}

As lifestyle interventions and weight management are key recommendations for the management of PCOS, identifying the most effective and acceptable lifestylerelated self-management strategies in this population may help support them in achieving lifestyle change and meeting the nutrition and physical activity recommendations as outlined in the 2018 evidence-based clinical guidelines for optimal PCOS management [140]. This will also inform the tailoring of PCOS lifestyle interventions for subgroups such as by BMI, age or medical history.

\section{Depression and body image distress}

Evidence-based guidelines recommend that all women with PCOS should be routinely screened for anxiety and depression symptoms at diagnosis and referred for psychological therapy if required. Initial screening questions and follow-up screening are provided in Table 1. Negative body image, which has been associated with poor sleep, can also be screened using a stepped approach, outlined in Table 1. Approaches to reduce body image distress include counselling based on acceptance and commitment therapy [141]. As with disordered eating and eating disorders, a weight-neutral approach is recommended for women with psychological comorbidities.

\section{Health literacy}

Involving women with PCOS in the co-development of health interventions or decisions is key to addressing the gap in critical health literacy, as demonstrated in recent research [142]. Better partnership between health professionals and women with PCOS has been highlighted as one of the key tenets of PCOS management in the latest evidence-based guidelines [10]. Building capacity among health professionals to be better partners with women with PCOS is among the strategic activities in the translation of the guidelines.

Wider adoption of evidence-based tool such as the AskPCOS smartphone application could improve communication between women with PCOS and health professionals (thereby improving interactive health literacy), since it includes a question prompt list that enables women with PCOS to discuss targeted health concerns with their healthcare providers [143, 144]. Additionally, further strategies to support peer groups should be developed and sustained to improve interactive health literacy in women with PCOS.

\section{Opportunity}

Considering the barriers of lack of time, childcare responsibilities and work commitment in women of reproductive age [14, 106], intervention targeting this group need to be flexible in structure and delivery to ensure engagement. Previous studies have seen success in lowintensity lifestyle intervention for weight gain prevention in women with young children [145], however, higher intensity interventions may be needed for weight loss [146]. The involvement of peers in exchanging ideas on how to overcome barriers to create more opportunities for healthy eating and physical activity within the context of the lives of women with PCOS may also be helpful [101] to expand opportunity, including using persuasion and incentivisation. Incentivisation may take the form of financial benefits, such as weekly financial incentives, return of initial deposits according to the number of sessions attended or completion of a program or, group incentives based on the attendance of individuals as a collective in each program group [147].

\section{Motivation \\ Risk perception and other barriers}

Despite limited evidence, there is a clear need for increased education, awareness, and accuracy of risk perception among women with PCOS. Shared decisionmaking and an improved understanding of the features of risk (including individual responses to risk aversion, risk immediacy, perceived vulnerabilities, consequences and control) are important considerations for successfully implementing lifestyle change [148]. However, adequate risk perception is insufficient on its own, and must be coupled with appropriate tools and resources to enable individuals to take preventive action [109]. Focusing on the reported successes of weight loss interventions in women with PCOS and providing strong encouragement about health-related issues may represent important targets for health professionals when counselling women with PCOS about the benefits of 
lifestyle modification. Further effort is required to communicate risks of unhealthy lifestyles to women with PCOS. Consistent with this approach, lifestyle messages for women with PCOS should be tailored to reflect the unique risk profiles of PCOS in terms of cardiometabolic disease prevention.

\section{Building intrinsic motivation}

Women should be encouraged to choose physical activities that they find enjoyable, rather than the ones they think they are expected to engage in (such as going to the gym). The use of mindfulness-based therapies is a potentially novel intervention that may help to enhance intrinsic motivation to exercise, and may have additional benefits for mental health [149].

\section{Behaviour}

\section{Overcoming attrition}

Our recent meta-analysis on strategies to reduce attrition in weight loss interventions for the general population included 57 studies and 7581 participants and reported that intervention strategies such as multicomponent interventions (nutrition, physical activity and behavioural strategies combined), monetary incentives (e.g. return of deposit following program completion or financial reward), and self-monitoring significantly reduce the risk of attrition in weight loss interventions[147]. Multi-component interventions included the use of weekly group sessions and behavioural technique education, behaviour change counselling and program reminders, self-monitoring and anti-stress management, self-monitoring with feedback or a chat platform for peer and professional support, weekly payments with pre-packaged foods, weekly group dietitian and psychology sessions, and energy restriction coupled with selfmonitoring and behavioural techniques. Self-monitoring encompassed paper and electronic devices to provide instant generalised or personalised feedback.

Within a clinical setting, financial incentives could be small cash payments, lottery tickets, grocery vouchers, or reduced-fee follow-up appointments to reward clinical attendance [147, 150-152]. Incentives greater than $1.2 \%$ of disposable income may be most beneficial to reduce attrition [153]. Research from the King's Fund in the United Kingdom found that the use of financial incentives are feasible in clinical settings but a mixture of positive (e.g. payment for attendance) and negative incentives (e.g. removal of refund or deposit return) must be included for optimal attendance and long-term behaviour change outcome[154].

Our systematic review highlighted a current lack of studies reporting attrition in female-only weight loss lifestyle interventions and we were unable to conduct subgroup analyses to determine the most effective attrition reducing strategies in females[147]. In another study we reported that women with PCOS presenting with depression symptoms upon program initiation are at greater odds of drop-out across lifestyle interventions [124]. Further studies aiming to assess the impact of attrition on behaviour change and weight loss in lifestyle interventions among females in both the general population and women with PCOS are needed [147]. Identifying intervention design factors that influence attrition in women with PCOS will help facilitate overall PCOS intervention effectiveness, helping to reduce the risk of PCOS associated disease [147].

\section{Conclusions}

There are a number of barriers to successful lifestyle change among women with PCOS. Emerging research suggests that a range of intrinsic factors for weight management may be altered in PCOS affecting the capability of women with PCOS to manage their weight, although this evidence is limited and currently inconsistent. Opportunity may be reduced due to systemic and general barriers which are compounded by PCOS-specific factors such as negative body image. Altered risk perception and a lack of intrinsic motivation (i.e. enjoyment) may affect motivation in women with PCOS. In assisting women to achieve their lifestyle goals, a multidisciplinary and multicomponent approach is required, incorporating self-management, behaviour change techniques to overcome barriers, screening and referral as appropriate for depression, negative body image, and eating disorders as per evidence-based guidelines, and overcoming health literacy gaps. More research needs to be conducted on overcoming attrition, gaps in risk perception, use of financial incentives and on tailoring recommendations for lifestyle change to be specific to women with PCOS.

\section{Abbreviations \\ BED: Binge-eating disorder; BMI: Body mass index; COMB: Capability \\ Opportunity Motivation Behaviour model; CVD: Cardiovascular disease; GLP- \\ 1: Glucagon-like peptide 1; OSA: Obstructive sleep apnoea; PCOS: Polycystic \\ Ovary Syndrome; RQ: Respiratory quotient}

\section{Acknowledgements}

Not applicable.

\section{Authors' contributions \\ CE and LM designed the work. CE, SP, AM, LM and SL contributed to equally to the acquisition, analysis and interpretation of the data; drafting of the manuscript; substantively revising the manuscript for intellectually important content; and approval of the submitted version.}

\section{Authors' information}

CE is a medical doctor (primary care physician).

SL, SP and LM are dietitians (accredited practising dietitian).

AM is a clinical scientist.

\section{Funding}

No funding was obtained to complete this manuscript. CE is supported by an endowment from the Jacka Foundation of Natural Therapies. LM is supported by a National Heart Foundation Future Leader Fellowship. AM 
and $\mathrm{SL}$ are supported by biomedical research fellowships from the National Health and Medical Research Council (NHMRC) of Australia.

\section{Availability of data and materials}

Not applicable.

\section{Declarations}

\section{Ethics approval and consent to participate}

None required.

\section{Consent for publication}

Not applicable.

\section{Competing interests}

The authors declare that they have no competing interests. As a medical research institute, NICM Health Research Institute receives research grants and donations from foundations, universities, government agencies, and industry. Sponsors and donors provide untied and tied funding for work to advance the vision and mission of the Institute.

\section{Author details}

${ }^{1}$ NICM Health Research Institute, Western Sydney University, Locked Bag 1797, NSW 2751 Penrith, Australia. ${ }^{2}$ Health and Social Care Unit, School of Public Health and Preventive Medicine, Monash University, 553 St. Kilda Road, VIC 3004 Melbourne, Australia. ${ }^{3}$ Monash Centre for Health Research and Implementation - MCHRI, School of Public Health and Preventive Medicine, Monash University, Level 1, 43-51 Kanooka Grove, VIC 3168 Clayton, Australia.

Received: 27 April 2021 Accepted: 28 October 2021 Published online: 23 November 2021

\section{References}

1. Teede H, Deeks A, Moran L. Polycystic ovary syndrome: a complex condition with psychological, reproductive and metabolic manifestations that impacts on health across the lifespan. BMC Med. 2010:8:41.

2. Bozdag G, Mumusoglu S, Zengin D, Karabulut E, Yildiz BO. The prevalence and phenotypic features of polycystic ovary syndrome: a systematic review and meta-analysis. Hum Reprod. 2016;31(12):2841-55.

3. Rotterdam ESHRE/ASRM-Sponsored PCOS Consensus Workshop Group. Revised 2003 consensus on diagnostic criteria and long-term health risks related to polycystic ovary syndrome. Fertil Steril. 2004;81(1):19-25.

4. Karjula S, Morin-Papunen L, Franks S, Auvinen J, Järvelin M-R, Tapanainen JS, Jokelainen J, Miettunen J, Piltonen TT. Population-based data at ages 31 and 46 show decreased HRQoL and life satisfaction in women with PCOS symptoms. J Clin Endocrinol Metab. 2020;105(6):1814-26.

5. Barry JA, Kuczmierczyk AR, Hardiman PJ. Anxiety and depression in polycystic ovary syndrome: a systematic review and meta-analysis. Hum Reprod. 2011:26(9):2442-51.

6. de Groot PCM, Dekkers OM, Romijn JA, Dieben SWM, Helmerhorst FM PCOS, coronary heart disease, stroke and the influence of obesity: a systematic review and meta-analysis. Hum Reprod Update. 2011;17(4):495500.

7. Stepto NK, Cassar S, Joham AE, Hutchison SK, Harrison CL, Goldstein RF, Teede HJ. Women with polycystic ovary syndrome have intrinsic insulin resistance on euglycaemic-hyperinsulaemic clamp. Hum Reprod. 2013;28(3): $777-84$

8. Teede HJ, Joham AE, Paul E, Moran LJ, Loxton D, Jolley D, Lombard C. Longitudinal weight gain in women identified with polycystic ovary syndrome: results of an observational study in young women. Obesity. 2013;21(8):1526-32.

9. Lim SS, Norman RJ, Davies MJ, Moran LJ. The effect of obesity on polycystic ovary syndrome: a systematic review and meta-analysis. Obes Rev. 2013; 14(2):95-109.

10. Teede HJ, Costello MF, Dokras A, Laven J, Misso M, Moran LJ, Piltonen T, Norman RJ. Recommendations from the international evidence-based guideline for the assessment and management of polycystic ovary syndrome. Hum Reprod. 2018;33(9):1602-1618.

11. Teede HJ, Joham AE, Paul E, Moran LJ, Loxton D, Jolley D, Lombard C. Longitudinal weight gain in women identified with Polycystic Ovary
Syndrome: results of an observational study in young women. Obesity. 2013;21(8):1526-32.

12. Lim SS, Hutchison SK, Van Ryswyk E, Norman RJ, Teede HJ, Moran LJ. Lifestyle changes in women with polycystic ovary syndrome. Cochrane Database Syst Rev. 2019;3:Cd007506.

13. Thomson ZO, Kelly JT, Sainsbury A, Reeves MM. Weight loss outcomes in premenopausal versus postmenopausal women during behavioral weight loss interventions: a systematic review and meta-analysis. Menopause. 2020; 28(3):337-46.

14. Lim S, Smith CA, Costello MF, MacMillan F, Moran L, Ee C. Barriers and facilitators to weight management in overweight and obese women living in Australia with PCOS: a qualitative study. BMC Endocr Disord. 2019;19(1): 106.

15. Michie S, Van Stralen MM, West R. The behaviour change wheel: a new method for characterising and designing behaviour change interventions. Implementation Sci. 2011;6(1):42.

16. Michie S, Atkins L, West R. The behaviour change wheel: a guide to designing interventions. Great Britain: Silverback Publishing; 2014.

17. Weight gain associated with intensive therapy in the diabetes control and complications trial. The DCCT Research Group. Diabetes Care. 1988;11(7): 567-573.

18. Welle S, Nair KS, Lockwood D. Effect of a sulfonylurea and insulin on energy expenditure in type II diabetes mellitus. J Clin Endocrinol Metab. 1988;66(3): 593-7.

19. Franssila-Kallunki A, Groop L. Factors associated with basal metabolic rate in patients with type 2 (non-insulin-dependent) diabetes mellitus. Diabetologia. 1992;35(10):962-6.

20. Ryan M, Livingstone MB, Ducluzeau PH, Salle A, Genaitay M, Ritz P. Is a failure to recognize an increase in food intake a key to understanding insulin-induced weight gain? Diabetes Care. 2008;31(3):448-50.

21. Carlson MG, Campbell PJ. Intensive insulin therapy and weight gain in IDDM. Diabetes. 1993:42(12):1700-7.

22. Kersten S. Mechanisms of nutritional and hormonal regulation of lipogenesis. EMBO Rep. 2001;2(4):282-6.

23. Felig P. Insulin is the mediator of feeding-related thermogenesis: insulin resistance and/or deficiency results in a thermogenic defect which contributes to the pathogenesis of obesity. Clin Physiol. 1984;4(4):267-73.

24. Pasquali R. Obesity and androgens: facts and perspectives. Fertil Steril. 2006; 85(5):1319-40

25. Georgopoulos NA, Saltamavros AD, Vervita V, Karkoulias K, Adonakis G, Decavalas G, Kourounis G, Markou KB, Kyriazopoulou V. Basal metabolic rate is decreased in women with polycystic ovary syndrome and biochemical hyperandrogenemia and is associated with insulin resistance. Fertil Steril. 2009:92(1):250-5.

26. Robinson S, Chan SP, Spacey S, Anyaoku V, Johnston DG, Franks S. Postprandial thermogenesis is reduced in polycystic ovary syndrome and is associated with increased insulin resistance. Clin Endocrinol. 1992;36(6):537-43.

27. Segal KR, Dunaif A. Resting metabolic rate and postprandial thermogenesis in polycystic ovarian syndrome. Int J Obes. 1990;14(7):559-67.

28. Churchill SJ, Wang ET, Bhasin G, Alexander C, Bresee C, Pall M, Azziz R, Mathur R, Pisarska MD. Basal metabolic rate in women with PCOS compared to eumenorrheic controls. Clin Endocrinol. 2015;83(3):384-8.

29. Romualdi D, Versace V, Tagliaferri V, De Cicco S, Immediata V, Apa R, Guido $\mathrm{M}$, Lanzone $\mathrm{A}$. The resting metabolic rate in women with polycystic ovary syndrome and its relation to the hormonal milieu, insulin metabolism, and body fat distribution: a cohort study. J Endocrinol Invest. 2019;42(9):108997.

30. Frayn KN. Calculation of substrate oxidation rates in vivo from gaseous exchange. J Appl Physiol Respir Environ Exerc Physiol. 1983:55(2):628-34.

31. Zurlo F, Lillioja S, Esposito-Del Puente A, Nyomba BL, Raz I, Saad MF, Swinburn BA, Knowler WC, Bogardus C, Ravussin E. Low ratio of fat to carbohydrate oxidation as predictor of weight gain: study of 24-h RQ. Am J Physiol. 1990;259(5 Pt 1):E650-657.

32. Seidell JC, Muller DC, Sorkin JD, Andres R. Fasting respiratory exchange ratio and resting metabolic rate as predictors of weight gain: the Baltimore Longitudinal Study on Aging. Int J Obes Relat Metab Disord. 1992;16(9): 667-74.

33. Larsson I, Hulthen L, Landen M, Palsson E, Janson P, Stener-Victorin E. Dietary intake, resting energy expenditure, and eating behavior in women with and without polycystic ovary syndrome. Clin Nutr. 2016; 35(1):213-8 
34. Rimmer M, Tan BK, Teede H, Thangaratinam S, B HAW. Metabolic inflexibility in women with polycystic ovary syndrome: a systematic review. Gynecol Endocrinol. 2020;36(6):501-7.

35. Gao T, Wu L, Chang F, Cao G. Low circulating ghrelin levels in women with polycystic ovary syndrome: a systematic review and meta-analysis. Endocr J. 2016:63(1):93-100.

36. O'Reilly MW, Kempegowda P, Walsh M, Taylor AE, Manolopoulos KN, Allwood JW, Semple RK, Hebenstreit D, Dunn WB, Tomlinson JW, et al. AKR1C3-mediated adipose androgen generation drives lipotoxicity in women with polycystic ovary syndrome. J Clin Endocrinol Metab. 2017; 102(9):3327-39.

37. Hirschberg AL, Naessen S, Stridsberg M, Bystrom B, Holtet J. Impaired cholecystokinin secretion and disturbed appetite regulation in women with polycystic ovary syndrome. Gynecol Endocrinol. 2004;19(2):79-87.

38. Lin T, Li S, Xu H, Zhou H, Feng R, Liu W, Sun Y, Ma J. Gastrointestinal hormone secretion in women with polycystic ovary syndrome: an observational study. Hum Reprod. 2015;30(11):2639-44.

39. Aydin K, Arusoglu G, Koksal G, Cinar N, Aksoy DY, Yildiz BO. Fasting and post-prandial glucagon like peptide 1 and oral contraception in polycystic ovary syndrome. Clin Endocrinol. 2014;81(4):588-92.

40. Moran L, Noakes M, Clifton PM, Wittert G, Tomlinson L, Galletly C, Luscombe N, Norman RJ. Ghrelin and measures of satiety are altered in polycystic ovary syndrome but not differentially affected by diet composition. Asia Pac J Clin Nutr. 2003;12:S52.

41. Japur CC, Diez-Garcia RW, de Oliveira Penaforte FR, das Gracas Pena G, de Araujo LB, de Sa MFS. Insulin, ghrelin and early return of hunger in women with obesity and polycystic ovary syndrome. Physiol Behav. 2019;206:252-258

42. Moran $\amalg$, Noakes M, Clifton PM, Wittert GA, Le Roux CW, Ghatei MA, Bloom SR, Norman RJ. Postprandial ghrelin, cholecystokinin, peptide YY, and appetite before and after weight loss in overweight women with and without polycystic ovary syndrome. Am J Clin Nutr. 2007;86(6):1603-10.

43. Daghestani MH, Daghestani M, Daghistani M, El-Mazny A, Bjorklund G, Chirumbolo S, Al Saggaf SH, Warsy A. A study of ghrelin and leptin levels and their relationship to metabolic profiles in obese and lean Saudi women with polycystic ovary syndrome (PCOS). Lipids Health Dis. 2018;17(1):195.

44. Arusoglu G, Koksal G, Cinar N, Tapan S, Aksoy DY, Yildiz BO. Basal and mealstimulated ghrelin, PYY, CCK levels and satiety in lean women with polycystic ovary syndrome: effect of low-dose oral contraceptive. J Clin Endocrinol Metab. 2013;98(11):4475-82.

45. Alsaadi HM, Van Vugt DA. Insulin sensitivity affects corticolimbic brain responses to visual food cues in polycystic ovary syndrome patients. Horm Mol Biol Clin Invest. 2015;24(2):101-15.

46. Dokras A, Stener-Victorin E, Yildiz BO, Li R, Ottey S, Shah D, Epperson N, Teede H. Androgen excess- polycystic ovary syndrome society: position statement on depression, anxiety, quality of life, and eating disorders in polycystic ovary syndrome. Fertil Steril. 2018;109(5):888-99.

47. Jeanes YM, Reeves S, Gibson EL, Piggott C, May VA, Hart KH. Binge eating behaviours and food cravings in women with Polycystic Ovary Syndrome. Appetite. 2017;109:24-32

48. Lee I, Cooney LG, Saini S, Sammel MD, Allison KC, Dokras A. Increased odds of disordered eating in polycystic ovary syndrome: a systematic review and meta-analysis. Eat Weight Disord Stud Anorexia Bulimia Obes. 2019;24:78797.

49. Tay CT, Teede HJ, Hill B, Loxton D, Joham AE. Increased prevalence of eating disorders, low self-esteem, and psychological distress in women with polycystic ovary syndrome: a community-based cohort study. Fertil Steril. 2019:112(2):353-61.

50. Naessén S, Söderqvist G, Carlström K. So similar and so different: circulating androgens and androgen origin in bulimic women. I Steroid Biochem Mol Biol. 2018;185:184-88.

51. Michelmore KF, Balen AH, Dunger DB. Polycystic ovaries and eating disorders: are they related? Hum Reprod. 2001;16(4):765-9.

52. Larsson I, Hulthén L, Landén M, Pålsson E, Janson P, Stener-Victorin E. Dietary intake, resting energy expenditure, and eating behavior in women with and without polycystic ovary syndrome. Clin Nutr. 2016;35(1):213-8

53. Karacan E, Caglar GS, Gürsoy AY, Yilmaz MB. Body satisfaction and eating attitudes among girls and young women with and without Polycystic Ovary Syndrome. J Pediatr Adolesc Gynecol. 2014;27(2):72-7.

54. Batcheller AE, Ressler IB, Sroga JM, Martinez AM, Thomas MA, DiPaola KB. Binge eating disorder in the infertile polycystic ovary syndrome patient. Fertil Steril. 2013;100(3):S413.
55. Sheehan DV, Lecrubier Y, Sheehan KH, Amorim P, Janavs J, Weiller E, Hergueta T, Baker R, Dunbar GC. The Mini-International Neuropsychiatric Interview (M.I.N.I.): the development and validation of a structured diagnostic psychiatric interview for DSM-IV and ICD-10. J Clin Psychiatry. 1998:59 Suppl 20:22-33. quiz 34-57.

56. Fairburn C, Cooper Z, O'Connor M. Eating disorder examination. In: Fairburn CG, editor. Cognitive behavior therapy and eating disorders. 16th ed. New York: Guildford Press; 2008.

57. Pirotta S, Barillaro M, Brennan L, Grassi A, Jeanes YM, Joham AE, Kulkarni J, Couch LM, Lim SS, Moran LJ. Disordered eating behaviours and eating disorders in women in Australia with and without Polycystic Ovary Syndrome: a cross-sectional study. J Clin Med. 2019;8:1682-94.

58. (NEDC) NEDC. Eating disorders prevention, treatment and management an updated evidence review. Sydney: NEDC; 2017.

59. Hollinrake E, Abreu A, Maifeld M, Van Voorhis BJ, Dokras A. Increased risk of depressive disorders in women with polycystic ovary syndrome. Fertil Steril. 2007;87(6):1369-76.

60. Azizi Kutenaee M, Amirjani S, Asemi Z, Taghavi SA, Allan H, Kamalnadian SN, Khashavi Z, Bazarganipour F. The impact of depression, self-esteem, and body image on sleep quality in patients with PCOS: a cross-sectional study. Sleep Breath. 2020;24(3):1027-34.

61. Thannickal A, Brutocao C, Alsawas M, Morrow A, Zaiem F, Murad MH, Javed Chattha A. Eating, sleeping and sexual function disorders in women with polycystic ovary syndrome (PCOS): a systematic review and meta-analysis. Clin Endocrinol. 2020;92(4):338-49.

62. Kahal H, Kyrou I, Uthman OA, Brown A, Johnson S, Wall PDH, Metcalfe A, Parr DG, Tahrani AA, Randeva HS. The prevalence of obstructive sleep apnoea in women with polycystic ovary syndrome: a systematic review and meta-analysis. Sleep Breath. 2020;24(1):339-50.

63. Senaratna CV, Perret JL, Lodge CJ, Lowe AJ, Campbell BE, Matheson MC, Hamilton GS, Dharmage SC. Prevalence of obstructive sleep apnea in the general population: a systematic review. Sleep Med Rev. 2017;34:70-81.

64. Moran LJ, March WA, Whitrow MJ, Giles LC, Davies MJ, Moore VM. Sleep disturbances in a community-based sample of women with polycystic ovary syndrome. Hum Reprod. 2015;30(2):466-72.

65. Mo L, Mansfield DR, Joham A, Cain SW, Bennett C, Blumfield M, Teede H, Moran $L$. Sleep disturbances in women with and without polycystic ovary syndrome in an Australian National Cohort. Clin Endocrinol. 2019;90(4):570-8.

66. Fernandez RC, Moore VM, Van Ryswyk EM, Varcoe TJ, Rodgers RJ, March WA, Moran LJ, Avery JC, McEvoy RD, Davies MJ. Sleep disturbances in women with polycystic ovary syndrome: prevalence, pathophysiology, impact and management strategies. Nat Sci Sleep. 2018;10:45-64.

67. Dokras A, Stener-Victorin E, Yildiz BO, Li R, Ottey S, Shah D, Epperson N, Teede H. Androgen Excess- Polycystic Ovary Syndrome Society: position statement on depression, anxiety, quality of life, and eating disorders in polycystic ovary syndrome. Fertil Steril. 2018;109(5):888-99.

68. Brutocao C, Zaiem F, Alsawas M, Morrow AS, Murad MH, Javed A. Psychiatric disorders in women with polycystic ovary syndrome: a systematic review and meta-analysis. Endocrine. 2018;62(2):318-25.

69. Cooney LG, Lee I, Sammel MD, Dokras A. High prevalence of moderate and severe depressive and anxiety symptoms in polycystic ovary syndrome: a systematic review and meta-analysis. Hum Reprod. 2017;32(5):1075-91.

70. Cooney LG, Lee I, Sammel MD, Dokras A. High prevalence of moderate and severe depressive and anxiety symptoms in polycystic ovary syndrome: a systematic review and meta-analysis. Hum Reprod. 2017;32(5):1075-91.

71. Farrell K, Antoni MH. Insulin resistance, obesity, inflammation, and depression in polycystic ovary syndrome: biobehavioral mechanisms and interventions. Fertil Steril. 2010;94(5):1565-74.

72. Banting LK, Gibson-Helm M, Polman R, Teede HJ, Stepto NK. Physical activity and mental health in women with polycystic ovary syndrome. BMC Womens Health. 2014;14(1):51.

73. Ekramzadeh M, Hajivandi L, Noroozi M, Mostafavi F. Psychological experiences of adolescent girls with Polycystic Ovary Syndrome: a qualitative study. Iran J Nurs Midwifery Res. 2020;25(4):341-7.

74. Pastore LM, Patrie JT, Morris WL, Dalal P, Bray MJ. Depression symptoms and body dissatisfaction association among polycystic ovary syndrome women. J Psychosom Res. 2011;71(4):270-6.

75. Alur-Gupta S, Chemerinski A, Liu C, Lipson J, Allison K, Sammel MD, Dokras A. Body-image distress is increased in women with polycystic ovary syndrome and mediates depression and anxiety. Fertil Steril. 2019;112(5): 930-938.e931. 
76. Himelein MJ, Thatcher SS. Depression and body image among women with polycystic ovary syndrome. J Health Psychol. 2006;11(4):613-25.

77. Baumeister RF, Vohs KD. Handbook of self-regulation: research, theory, and applications. The Guilford Press. New York; 2004.

78. Burman JT, Green CD, Shanker S. On the meanings of self-regulation: digital humanities in service of conceptual clarity. Child Dev. 2015;86(5):1507-21.

79. Lorig KR, Holman H. Self-management education: history, definition, outcomes, and mechanisms. Ann Behav Med. 2003;26(1):1-7.

80. Corbin JM, Strauss A. Unending work and care: managing chronic illness at home. San Francisco: Jossey-Bass; 1988.

81. Ryan P, Sawin KJ. The individual and family self-management theory: background and perspectives on context, process, and outcomes. Nurs Outlook. 2009:57(4):217-225.e216.

82. Marks R, Allegrante JP. A review and synthesis of research evidence for selfefficacy-enhancing interventions for reducing chronic disability: implications for health education practice (Part II). Health Promot Pract. 2005;6(2):148-56.

83. Dineen-Griffin S, Garcia-Cardenas V, Williams K, Benrimoj SI. Helping patients help themselves: a systematic review of self-management support strategies in primary health care practice. PLoS One. 2019;14(8):e0220116.

84. Nutbeam D. Health promotion glossary. Health Promot. 1986;1(1):113-27.

85. Berkman ND, Sheridan SL, Donahue KE, Halpern DJ, Crotty K. Low health literacy and health outcomes: an updated systematic review. Ann Intern Med. 2011;155(2):97-107.

86. Cheng Y-L, Shu J-H, Hsu H-C, Liang Y, Chou R-H, Hsu P-F, Wang Y-J, Ding Y$Z$, Liou T-L, Wang $Y-W$, et al. High health literacy is associated with less obesity and lower Framingham risk score: Sub-study of the VGHHEALTHCARE trial.(Research Article). PloS one. 2018;13(3):e0194813.

87. Cheong SM, Mohamad Nor NS, Ahmad MH, Manickam M, Ambak R, Shahrir SN, Aris T. Improvement of health literacy and intervention measurements among low socio-economic status women: findings from the MyBFF@home study. BMC Womens Health. 2018;18(1):99.

88. Abdollahi M, Peyman N. The effect of an educational program based on health literacy strategies on physical activity in postpartum women. J Midwifery Reprod Health. 2017;5(4):1059-65.

89. Al-Ruthia YS, Balkhi B, AlGhadeer S, Mansy W, AlSanawi H, AlGasem R, AlMutairi L, Sales I. Relationship between health literacy and body mass index among Arab women with polycystic ovary syndrome. Saudi Pharm J. 2017;25(7):1015-8

90. Lim S, Smith CA, Costello MF, MacMillan F, Moran L, Teede H, Ee C. Health literacy needs in weight management of women with Polycystic Ovary Syndrome. Health Promot J Austr. 2020;32(S1):41-48.

91. Nutbeam D. Health literacy as a public health goal: a challenge for contemporary health education and communication strategies into the $21 \mathrm{st}$ century. Health Promot Int. 2000;15(3):259-267.

92. Berkman ND, Sheridan SL, Donahue KE, Halpern DJ, Crotty K. Low health literacy and health outcomes: an updated systematic review. Ann Intern Med. 2011;155(2):97-107.

93. Moran LJ, Brown WJ, McNaughton SA, Joham AE, Teede HJ. Weight management practices associated with PCOS and their relationships with diet and physical activity. Hum Reprod. 2017;32(3):669-78.

94. Humphreys L, Costarelli V. Implementation of dietary and general lifestyle advice among women with polycystic ovarian syndrome. J R Soc Promot Health. 2008;128(4):190-5.

95. Jeanes YM, Barr S, Smith K, Hart KH. Dietary management of women with polycystic ovary syndrome in the United Kingdom: the role of dietitians. J Hum Nutr Diet. 2009;22(6):551-8.

96. Michie S, Abraham C, Whittington C, McAteer J, Gupta S. Effective techniques in healthy eating and physical activity interventions: a metaregression. Health Psychol. 2009;28(6):690-701.

97. Osborne RH, Batterham RW, Elsworth GR, Hawkins M, Buchbinder R. The grounded psychometric development and initial validation of the Health Literacy Questionnaire (HLQ). BMC Public Health. 2013;13:658.

98. Avery JC, Braunack-Mayer AJ. The information needs of women diagnosed with Polycystic Ovarian Syndrome--implications for treatment and health outcomes. BMC Womens Health. 2007;7:9

99. Bazarganipour F, Taghavi SA, Allan H, Hosseini N. Facilitating and inhibiting factors related to treatment adherence in women with polycystic ovary syndrome: a qualitative study. Int J Reprod Biomed. 2017;15(9):553-60.

100. Crete J, Adamshick P. Managing polycystic ovary syndrome: what our patients are telling us. J Holist Nurs. 2011;29(4):256-66.
101. Avery J, Ottey S, Morman R, Cree-Green M, Gibson-Helm M. Polycystic ovary syndrome support groups and their role in awareness, advocacy and peer support: a systematic search and narrative review. Curr Opin Endocr Metab Res. 2020;12:98-104.

102. Ee C, Smith C, Moran L, MacMillan F, Costello M, Baylock B, Teede H. "The whole package deal": experiences of overweight/obese women living with polycystic ovary syndrome. BMC Womens Health. 2020;20(1):221.

103. Nutbeam D. The evolving concept of health literacy. Soc Sci Med. 2008; 67(12):2072-8

104. Chinn D. Critical health literacy: a review and critical analysis. Soc Sci Med. 2011;73(1):60-7.

105. Garad R, McPhee C, Chai TL, Moran L, O'Reilly S, Lim S. The role of health literacy in postpartum weight, diet, and physical activity. J Clin Med. 2020; 9(8):1-14.

106. Andajani-Sutjahjo S, Ball K, Warren N, Inglis V, Crawford D. Perceived personal, social and environmental barriers to weight maintenance among young women: a community survey. Int J Behav Nutr Phys Act. 2004;1(1):15.

107. Adamson L, Brown W, Byles J, Chojenta C, Dobson A, Fitzgerald D, Hockey $R$, Loxton D, Powers J, Spallek M, et al. Women's weight: findings from the Australian Longitudinal Study on Women's Health. In. Edited by Ageing AGDoHa. 2007.

108. Lim S, Smith CA, Costello MF, MacMillan F, Moran L, Ee C. Barriers and facilitators to weight management in overweight and obese women living in Australia with PCOS: a qualitative study. BMC Endocr Disord. 2019;19(1): 106.

109. Inouye J. Risk perception: theories, strategies and next steps. In. Edited by Council NS. Itasca: Campbell Institute; 2014.

110. DiLorenzo TA, Schnur J, Montgomery GH, Erblich J, Winkel G, Bovbjerg DH. A model of disease-specific worry in heritable disease: the influence of family history, perceived risk and worry about other illnesses. J Behav Med. 2006;29(1):37-49.

111. Erblich J, Bovbjerg DH, Norman C, Valdimarsdottir HB, Montgomery GH. It won't happen to me: lower perception of heart disease risk among women with family histories of breast cancer. Prev Med. 2000;31(6):714-21.

112. Kozica SL, Gibson-Helm ME, Teede HJ, Moran LJ. Assessing self-efficacy and self-help methods in women with and without polycystic ovary syndrome. Behav Med. 2013;39(3):90-6.

113. Moran L, Gibson-Helm M, Teede H, Deeks A. Polycystic ovary syndrome: a biopsychosocial understanding in young women to improve knowledge and treatment options. J Psychosom Obstet Gynaecol. 2010;31(1):24-31.

114. Colwell K, Lujan ME, Lawson KL, Pierson RA, Chizen DR. Women's perceptions of polycystic ovary syndrome following participation in a clinical research study: implications for knowledge, feelings, and daily health practices. J Obstet Gynaecol Can. 2010;32(5):453-9.

115. Humphreys L, Costarelli V. Implementation of dietary and general lifestyle advice among women with polycystic ovarian syndrome. J R Soc Promot Health. 2008;128(4):190-5.

116. Lin AW, Dollahite JS, Sobal J, Lujan ME. Health-related knowledge, beliefs and self-efficacy in women with polycystic ovary syndrome. Hum Reprod. 2018:33(1):91-100.

117. Kakoly NS, Khomami MB, Joham AE, Cooray SD, Misso ML, Norman RJ, Harrison CL, Ranasinha S, Teede HJ, Moran $\sqcup$. Ethnicity, obesity and the prevalence of impaired glucose tolerance and type 2 diabetes in PCOS: a systematic review and meta-regression. Hum Reprod Update. 2018;24(4): 455-67.

118. Lim SS, Kakoly NS, Tan JWJ, Fitzgerald G, Bahri Khomami M, Joham AE, Cooray SD, Misso ML, Norman RJ, Harrison CL, et al. Metabolic syndrome in polycystic ovary syndrome: a systematic review, meta-analysis and metaregression. Obes Rev. 2019;20(2):339-352.

119. Cussons AJ, Stuckey BG, Walsh JP, Burke V, Norman RJ. Polycystic ovarian syndrome: marked differences between endocrinologists and gynaecologists in diagnosis and management. Clin Endocrinol. 2005;62(3): 289-95.

120. Jeanes Y, Barr S, Smith K, Hart K. Dietary management of women with polycystic ovary syndrome in the United Kingdom: the role of dietitians. J Hum Nutr Diet. 2009;22(6):551-8.

121. Thomson RL, Buckley JD, Brinkworth GD. Perceived exercise barriers are reduced and benefits are improved with lifestyle modification in overweight and obese women with polycystic ovary syndrome: a randomised controlled trial. BMC Womens Health. 2016;16:14-14. 
122. Teixeira PJ, Going SB, Houtkooper LB, Cussler EC, Metcalfe LL, Blew RM, Sardinha LB, Lohman TG. Pretreatment predictors of attrition and successful weight management in women. Int J Obes. 2004;28(9):1124-33.

123. Moran LJ, Hutchison SK, Norman RJ, Teede HJ. Lifestyle changes in women with polycystic ovary syndrome. Cochrane Database Syst Rev. 2011;16(2): Cd007506.

124. Moran $L$, Noakes M, Clifton P, Buckley J, Brinkworth G, Thomson R, Norman RJ. Predictors of lifestyle intervention attrition or weight loss success in women with polycystic ovary syndrome who are overweight or obese. Nutrients. 2019;11(3):1-13.

125. Moran L, Hutchison SK, Norman RJ, Teede HJ. Lifestyle changes in women with polycystic ovary syndrome. Cochrane Database Syst Rev. 2011;16(2): Cd007506.

126. Kim CH, Chon SJ, Lee SH. Effects of lifestyle modification in polycystic ovary syndrome compared to metformin only or metformin addition: a systematic review and meta-analysis. Sci Rep. 2020;10(1):7802.

127. Finley CE, Barlow CE, Greenway FL, Rock CL, Rolls BJ, Blair SN. Retention rates and weight loss in a commercial weight loss program. Int J Obes (Lond). 2007;31(2):292-8.

128. De Panfilis C, Torre M, Cero S, Salvatore P, Dall'Aglio E, Marchesi C, Cabrino C, Aprile S, Maggini C. Personality and attrition from behavioral weight-loss treatment for obesity. Gen Hosp Psychiatry. 2008;30(6):515-20.

129. Greenberg I, Stampfer MJ, Schwarzfuchs D, Shai I. Adherence and success in long-term weight loss diets: the dietary intervention randomized controlled trial (DIRECT). J Am Coll Nutr. 2009;28(2):159-68.

130. Han TS, Lean ME. A clinical perspective of obesity, metabolic syndrome and cardiovascular disease. JRSM Cardiovasc Dis. 2016;5:2048004016633371.

131. Honas JJ, Early JL, Frederickson DD, O'Brien MS. Predictors of attrition in a large clinic-based weight-loss program. Obes Res. 2003;11(7):888-94.

132. Leung AWY, Chan RSM, Sea MMM, Woo J. An overview of factors associated with adherence to lifestyle modification programs for weight management in adults. Int J Environ Res Public Health. 2017;14(8):922.

133. Gill RS, Karmali S, Hadi G, Al-Adra DP, Shi X, Birch DW. Predictors of attrition in a multidisciplinary adult weight management clinic. Can J Surg. 2012; 55(4):239-43.

134. Miller BML, Brennan L. Measuring and reporting attrition from obesity treatment programs: a call to action! Obes Res Clin Pract. 2015;9(3):187202.

135. Netzer NC, Stoohs RA, Netzer CM, Clark K, Strohl KP. Using the Berlin Questionnaire to identify patients at risk for the sleep apnea syndrome. Ann Intern Med. 1999;131(7):485-91.

136. Teede H, Misso M, Costello M, Dokras A, Laven J, Moran L, Piltonen T, Norman R, Network obotlP. International evidence- based guideline for the assessment and management of polycystic ovary syndrome. Melbourne: Monash University; 2018.

137. American Psychiatric Association. Diagnostic and statistical manual of mental disorders. 5th ed. Arlington: American Psychiatric Association; 2013.

138. Mensinger JL, Calogero RM, Stranges S, Tylka TL. A weight-neutral versus weight-loss approach for health promotion in women with high BMI: a randomized-controlled trial. Appetite. 2016;105:364-74.

139. Dugmore JA, Winten CG, Niven HE, Bauer J. Effects of weight-neutral approaches compared with traditional weight-loss approaches on behavioral, physical, and psychological health outcomes: a systematic review and meta-analysis. Nutr Rev. 2020;78(1):39-55.

140. Monash University. International evidence based guideline for the assessment and management of polycystic ovary syndrome. Melbourne: Monash University; 2018

141. Moradi F, Ghadiri-Anari A, Dehghani A, Reza Vaziri S, Enjezab B. The effectiveness of counseling based on acceptance and commitment therapy on body image and self-esteem in polycystic ovary syndrome: an RCT. Int J Reprod Biomed. 2020;18(4):243-52.

142. Pirotta S, Joham AJ, Moran LJ, Skouteris H, Lim SS. Implementation of evidence-based PCOS lifestyle management guidelines: perceived barriers and facilitators by consumers using the Theoretical Domains Framework and COM-B Model. Patient Educ Couns. 2021.

143. Khan NN, Vincent A, Boyle JA, Burggraf M, Pillay M, Teede H, Gibson-Helm M. Development of a question prompt list for women with polycystic ovary syndrome. Fertil Steril. 2018;110(3):514-22.

144. Xie J, Burstein F, Garad R, Teede HJ, Boyle JA. Personalized mobile tool AskPCOS delivering evidence-based quality information about polycystic ovary syndrome. Semin Reprod Med. 2018;36(1):66-72.
145. Lombard C, Deeks A, Jolley D, Ball K, Teede H. A low intensity, community based lifestyle programme to prevent weight gain in women with young children: cluster randomised controlled trial. Bmj. 2010;341:c3215.

146. American College of Cardiology/American Heart Association Task Force on Practice Guidelines OEP. Expert panel report: guidelines (2013) for the management of overweight and obesity in adults. Obesity (Silver Spring). 2014;22(Suppl 2):S41-410.

147. Pirotta S, Joham A, Hochberg L, Moran L, Lim S, Hindle A, Brennan L. Strategies to reduce attrition in weight loss interventions: a systematic review and meta-analysis. Obes Rev. 2019;20(10):1400-12.

148. Ortendahl M. Shared decision-making based on different features of risk in the context of diabetes mellitus and rheumatoid arthritis. Ther Clin Risk Manage. 2007;3(6):1175-80.

149. Ruffault A, Bernier M, Juge N, Fournier JF. Mindfulness may moderate the relationship between intrinsic motivation and physical activity: a crosssectional study. Mindfulness. 2016;7(2):445-52.

150. Post EP, Cruz M, Harman J. Incentive payments for attendance at appointments for depression among low-income African Americans. Psychiatr Serv. 2006;57(3):414-6.

151. Rice JM, Lutzker JR. Reducing noncompliance to follow-up appointment keeping at a family practice center. J Appl Behav Anal. 1984;17(3):303-11.

152. Laken MP, Ager J. Using incentives to increase participation in prenatal care. Obstet Gynecol. 1995;85(3):326-9.

153. Paul-Ebhohimhen V, Avenell A. Systematic review of the use of financial incentives in treatments for obesity and overweight. Obes Revi. 2008;9(4): 355-67.

154. Jochelson K. Paying the patient: improving health using financial incentives. London: Kings Fund; 2007.

\section{Publisher's Note}

Springer Nature remains neutral with regard to jurisdictional claims in published maps and institutional affiliations.

Ready to submit your research? Choose BMC and benefit from

- fast, convenient online submission

- thorough peer review by experienced researchers in your field

- rapid publication on acceptance

- support for research data, including large and complex data types

- gold Open Access which fosters wider collaboration and increased citations

- maximum visibility for your research: over $100 \mathrm{M}$ website views per year

At BMC, research is always in progress.

Learn more biomedcentral.com/submissions 